\title{
CRISE E POPULISMO: CONCEITOS E IMPLICAÇÕES
}

CRISIS AND POPULISM: CONCEPTS AND ITS IMPLICATIONS

\section{Felipe Maia}

Felipe Maia é sociólogo, professor no Departamento de Ciências Sociais e no Programa de Pós-Graduação em Ciências Sociais da Universidade Federal de Juiz de Fora (UFJF). Atua principalmente nas áreas de teoria social, sociologia política e pensamento social brasileiro. É coordenador do projeto de pesquisa "Crises e críticas: intelectuais, teoria e processos sociais", com recursos da Fundação de Amparo à Pesquisa do Estado de Minas Gerais (FAPEMIG), que apoiaram também a produção deste artigo.

Alessandra Faria

Alessandra Maia Terra de Faria é cientista social e professora de teoria política, sociologia política e instituições políticas na Pontifícia Universidade Católica do Rio de Janeiro (PUC-Rio), e no programa de Pós-graduação em Ciências Sociais da Universidade Federal Rural do Rio de Janeiro (UFRRJ). Atualmente também desenvolve sua primeira tradução de livro em estágio de pós-doutoramento no Programa de Pós-graduação em Ciências Sociais e no Programa de Pós-graduação em Estudos da Linguagem da PUC-Rio. Publicou livros e capítulos de livros na área de ciência política no Brasil, na Argentina e na Alemanha, e cerca de dez artigos acadêmicos. 


\section{RESUMO}

Este artigo apresenta recortes da literatura sobre populismo e crises políticas. Visa discutir tais temas tendo em vista a hipótese de que o populismo pode ser uma resposta à crise, ou que é possível identificar linguagens conceituais próprias que informam seus significados. Tais linguagens conceituais, compostas por várias camadas de significados múltiplos, são atribuídas tanto pela literatura, quanto pelos atores sociais e políticos; o que se conforma em múltiplos sentidos em disputa na formação de consciências de crise. Nesse sentido, o populismo se manifesta como uma "política" de crise no contexto atual. Para analisá-la, propõe-se, então, articular os dois conceitos - crise e populismo - à luz de algumas das teorias que tratam dos temas da democracia e da representação.

Palavras-chave: crise; populismo; conceitos; democracia; representação.

\section{ABSTRACT}

This article presents excerpts from the literature on populism and political crises. It aims to discuss these themes in view of the hypothesis, whatever, that populism can be a response to the crisis, or it is possible to identify its own conceptual languages that inform its meanings. Such conceptual languages, composed of several layers of multiple meanings, are attributed both by literature and by social and political actors. What conforms in multiple senses in dispute in the formation of crisis consciousness. In this sense, populism manifests itself as a "politics" of crisis in the current context. To analyze it, the article then proposes to articulate the two concepts - crisis and populism - in the light of some of the theories that deal with the themes of democracy and representation.

Keywords: crisis; populism; concepts; democracy; representation. 


\section{Introdução}

A escalada de problemas e processos sociais, políticos e culturais percebidos como crise no presente vem motivando uma retomada do debate na literatura sobre democracia e representação a respeito do conceito de crise, e a linguagem conceitual característica que envolve sua análise. A controvérsia acerca do sentido e de sua utilidade favorece a autorreflexividade da teoria sobre suas limitações e estratégias interpretativas dos processos sociais. Sem tomar a crise como um referente natural estabilizado, mas sem resvalar para soluções mais cômodas do nominalismo, o debate deve permitir que se encontre critérios para mapear as relações entre as lógicas ou dinâmicas sistêmicas de crise e os processos de formação de consciência de crise que transcorrem por meio de comunicações em esferas públicas.

As crises podem, assim, ser teorizadas em sua complexidade e historicidade sem necessariamente apoiar-se em filosofias da história abrangentes. Um exemplo vinculativo nesse sentido foi o trabalho de Reinhart Koselleck, que associa fortemente a "atual crise mundial" de seu tempo à história europeia..$^{1}$ Por outro lado, a abertura para as experiências de crise, a "crise vivida", restaura a centralidade da linguagem na produção da vida social em suas distintas e desiguais condições. Com ela, a experiência política pode ser pensada em sua dimensão específica que, se não se constitui como um centro totalizante e unificador do social, tem, no entanto, formas próprias de constituir representações das sociedades sobre si mesmas e concentra recursos que permitem ações e coordenação de ações em larga escala.

\section{Referências para linguagem, agência e crise em Hanna Pitkin}

A experiência política, nesse sentido, com base em análises da filosofia da linguagem ordinária, como propostas em pesquisas de Hanna Pitkin (1993), auxilia a reflexividade sobre o tema da crise. Com o estudo de Wittgenstein, Pitkin recupera o debate sobre os conceitos e o mundo da vida. Nosso sistema conceitual que governa o que podemos dizer sobre a realidade, certamente também afeta o que percebemos a seu respeito. Ou seja, os conceitos que usamos para lidar com as crises afetam o que tendemos a notar ou lembrar. Segundo Wittgenstein, relembra Pitkin, "os conceitos 'nos conduzem às investigações'; eles não são meramente 'a expressão de nosso interesse', mas também 'conduzem nosso interesse”" (PITKIN, I993, p. I38, tradução nossa).

\footnotetext{
${ }^{1}$ Segundo observa o autor: "A crise política (que, uma vez deflagrada, exige uma decisão) e as respectivas filosofias da história (em cujo nome tenta-se antecipar esta decisão, influenciá-la, orientá-la, ou, em caso de catástrofe, evitá-la) formam um único fenômeno histórico, cuja raiz deve ser procurada no século XVIII" (KOSELLECK, 1999, p. 9).
} 
Mas isso não significa necessariamente que nossos conceitos determinem a realidade por completo. A autora considera que é possível uma alternativa ao determinismo linguístico (no estilo da filosofia de Whorf, por exemplo), com uma postura que busque manter um equilíbrio dialético entre as influências mútuas da linguagem e do mundo. A questão conceitual básica sobre a relação entre as palavras e o mundo não permite uma resposta única e consistente, mas pode ser substituída por todo um conjunto de perguntas mais específicas que alcançam respostas consistentes e são esclarecedoras.

Com isso, Pitkin oferece uma boa entrada para lidar com paradoxos conceituais que ajuda a problematizar a "crise" e o "populismo" como conceitos e fenômenos políticos. Segundo afirma a autora, pensadores políticos devem se debruçar sobre a pluralidade, a ambiguidade e a contradição. Tal investida deve ter a preocupação não apenas com determinada dinâmica que afete um pequeno grupo, mas que afete outras pessoas, algumas delas bem distantes e estranhas, seja aos outros seja a quem analisa. Para ser de fato político (political), o pensamento não pode se restringir a tópicos que afetem apenas pequenos círculos, mas sim algo que se amplie no sentido de apoiar a ação participativa comunitária em prol de interesses comuns (PITKIN, 20I6).

Apenas se mantida uma constelação de preocupações em mente: contradições, pluralidades e contextos particulares, por um lado; e conexões difusas, por outro; e apenas se a abordagem consegue reconhecer as tensões inerentes à essas perspectivas, será possível predicar juízo e ação políticos que permitam que o pensamento político esteja de fato empenhado.

Considerar a ambivalência não significa usá-la para justificar inações, mas levá-la em consideração para habilitar e informar juízos práticos sobre o que fazer. Para Pitkin(20I6), dilemas de teorização têm características conceituais, históricas e psicológicas observáveis. Ao estudar de perto textos canônicos (como os de Maquiavel, por exemplo), a autora desenvolve análises textuais e históricas, não apenas em busca de um significado contextual do texto. Seu objetivo é explorar modos pelos quais as tensões subliminares fortalecem o engajamento público (e a participação política), e por isso conformam partes intrínsecas ao pensamento político em si. Ou seja, é uma postura epistemológica estar a par das tentações na escrita acadêmica e teórica sobre a tendência de desviar das ambivalências engendradas por múltiplas tensões e ignorar dilemas que se apresentam ao pensamento político.

A recomendação que se pode adotar de Pitkin vai nesse sentido, como deixar de lado - por exemplo, ao estudar crise e populismo - convenções e clichês, e ir ao encontro dos problemas; considerar ao mesmo tempo dimensões de larga escala e longa duração, sem desprezar o grau de orientação para a ação, a prática, a fala em sentido significativo e capaz de promover mudanças (PITKIN, 1987, 1993). Uma das principais contribuições das análises e dos métodos de estudo da autora 
vem exatamente do seu trabalho sobre a linguagem e seu uso da análise semântica. A importância em compreender que os problemas que surgem do ponto de vista teórico na política devem ser considerados em relação a conceitos que refletem problemas vivenciados na experiência política.

Quando se passa da dimensão do contexto para a agência, percebe-se que a ação (condicionada pelo contexto) é uma tentativa de resposta à crise (uma política de crise) e que, para isso, oferece um entendimento "simples" para problemas complexos. Produz um modo de representar a sociedade para si mesma e justifica determinadas linhas de ação adotadas no governo. Essa abordagem implica tomar o populismo não apenas como um "conceito de combate" (o que também é), isto é, uma categoria de acusação ("negativa”) de adversários políticos, mas compreender seus aspectos "positivos" (sua "doutrina", centrada no modo como concebem a democracia e a representação) e suas possíveis consequências.

Se seguimos Rosanvallon (202I), a avaliação do populismo e, poderíamos acrescentar, das políticas de crise, não se direciona apenas ao conteúdo programático das políticas propostas pelas várias lideranças e movimentos, mas para além disso, a aspectos menos conjunturais, mais institucionais e mais voltados à cultura política que conformam repertórios para lidar com conflitos e crises - daí a centralidade de concepções de democracia e representação, que podem sobreviver às crises conjunturais.

Por isso, da perspectiva de uma teoria crítica da crise, importa enfrentar não só os programas políticos efetivos de movimentos populistas que, à direita, assumem feições xenófobas, oligárquicas e abertamente autoritárias, mas também as formulações doutrinárias e teóricas que os acompanham e que não se restringem a essa posição no espaço político, tais como a representação dual da sociedade e do conflito, conforme esquemas amigo-inimigo, a representação unitária da liderança política ou a concepção majoritária de democracia. É o exame da lógica, e não apenas das "intenções", que permite tornar mais claras as limitações, as consequências não intencionais, mas previsíveis do populismo como rota de fuga, como formação de consciência e política de crise.

A crítica proposta neste artigo se faz em nome de mais, e não menos democracia. Daí que a "terapia" não possa ser a simples manutenção do status quo das democracias liberais (ou neoliberais), mas um avanço em direção a formas deliberativas e participativas. São elas que poderiam permitir a constituição dos mecanismos reflexivos necessários para lidar com crises complexas, com base em requisitos normativos de justiça e participação, como será esclarecido ao longo do texto. 


\section{A crise como um modelo cultural}

Desse modo, a proposta aqui é desenvolver o conceito de crise como parte decisiva da interpretação, e não como um simples contexto, cenário ou pano de fundo conjuntural, nem como categoria totalizante de uma filosofia da história. Importa, pois, pensar o que se faz quando se avalia uma situação como de "crise" e que sentidos ela assume em conjunturas determinadas, isto é, como ela se torna parte de contextos e situações. De modo mais amplo, o conceito de crise se constitui como um "modelo cultural" (STRYDOM, 2OII) que pode ser acionado para lidar com o entroncamento de problemas que afetam tanto operações sistêmicas quanto o quadro normativo da vida social. A longa história semântica da palavra "crise" nas línguas ocidentais, a despeito de seus significados localizados, testemunha a sedimentação da ideia de crise como expressão de algo que vai além de um mal-estar, que procura dar conta de momentos em que exacerbam-se incertezas e contradições, em que rotinas e operações sistêmicas falham, produzindo a sensação de descontinuidade ou até de ruptura na dinâmica social (CORDERO, 2OI4; MAIA, 202I). Ao mesmo tempo, o modelo cultural contém elementos destacadamente agenciais, ${ }^{2}$ tanto no que diz respeito ao diagnóstico de causalidades, quanto à sua capacidade de mobilização de formas de ação coletiva (MILSTEIN, 2015). Crises, nesse sentido, são distintas de tragédias e catástrofes, na medida em que a agência humana é parte constitutiva da concepção dos problemas, o que envolve o conflito em torno da atribuição de responsabilidades e o descortínio de linhas de ação terapêuticas e transformativas. Em torno das crises, constituem-se "políticas de crise".

Pode-se ver como Jürgen Habermas propôs um caminho que procura combinar essa dupla dimensão sistêmica e normativa na teorização de crises. Seu estudo sobre o "capitalismo tardio" europeu do pós-guerra apontava para uma dinâmica de deslocamentos de contradições e conflitos decorrentes da estruturação de classes do capitalismo do terreno estritamente econômico para o político. Para ele, a lógica das crises do capitalismo tardio estava ligada a uma sobrecarga do aparato político-administrativo que precisava lidar com a mediação de interesses contraditórios na estrutura de classes e com os limites funcionais de sua capacidade administrativa. A perda de desempenho estatal tendia a gerar descontentamento e problemas de legitimação política. Para além disso, a subsunção crescente de um conjunto de esferas da vida social à administração pública e as dinâmicas de insulamento da administração em relação a demandas democráticas de participação política tendiam a produzir crises de "motivação", que estariam na origem de uma nova leva de protestos e movimentos sociais, nos quais ele identificava um potencial democrático (HABERMAS, I988).

\footnotetext{
${ }^{2}$ Sobre o tema da agência e do discurso moral com base na filosofia da linguagem ordinária, ver Pitkin (1993, p. 140-168).
} 
Esses protestos apontavam para a limitação das capacidades dos sistemas funcionalmente diferenciados, em especial os subsistemas econômico e jurídico-administrativo, de produzir modos de integração compatíveis com as novas expectativas culturais e normativas, que se dão por meio de práticas cotidianas de comunicação e entendimento não redutíveis às formas de codificação e controle característicos das operações sistêmicas. As tendências de crise podem ser teorizadas com base nos paradoxos decorrentes de um desenvolvimento desigual e desacoplado dos processos de racionalização dos sistemas, cada vez mais complexos, e do mundo da vida sociocultural, menos tradicional e mais reflexivo, menos sujeito à administração ideológica da cultura e da participação política passiva. O quadro sugere, então, a existência de tendências e contratendências no que diz respeito aos macroprocessos de racionalização, reflexividade e controle. O diagnóstico crítico aponta para os riscos "patológicos" de colonização do mundo da vida por imperativos sistêmicos (HABERMAS, 2OI2).

Para Habermas (2003), os estados democráticos de direito procuraram contornar esses problemas, constituindo, por meio do direito, processos de comunicação entre o sistema político, suas instituições e uma esfera pública de redes e associações, nos quais os conflitos podem ser processados por operações no núcleo do sistema, que segue certas rotinas de produção regular de decisões em tribunais, na administração ou no parlamento. Por um lado, importa saber o quanto essas rotinas nos núcleos decisórios são efetivamente abertas aos influxos oriundos da "periferia" e como se dão os processos de formação da atenção pública e de "problematização". Por outro lado, é preciso ver o que acontece em situações de conflito ou como emerge uma "consciência de crise".

A crise aparece, então, associada a uma distinção entre o modo "normal" (ou rotineiro) e o extraordinário de solução de problemas, segundo um conceito discursivo de direito democrático. Nele, a institucionalização do processamento de conflitos não imuniza a legitimação da autoridade política com relação a crises. As tentativas de contornar o problema com recursos paternalistas, corporativistas ou tecnocráticos, como tematizado na teoria política das elites ou na teoria dos sistemas, elidindo as necessidades comunicativas de problematização de "problemas das sociedades como um todo", não dão conta das necessidades de integração de práticas comunicativas que encontram melhor acolhida em uma esfera pública não funcionalizada administrativamente. É nessa esfera virtual de comunicação que, a depender da qualidade comunicativa de seus procedimentos, pode-se formar um público e uma consciência de crise capaz de influenciar os sistemas políticos em torno de "problemas das sociedades como um todo". Quando isso acontece, tornar-se-ia possível alterar os fluxos normalizados do poder político-administrativo.

O argumento de Habermas depende de uma reconstrução conceitual de um modelo de política deliberativa, no qual a esfera pública cumpre funções de mediação entre uma sociedade civil 
descentrada e sistemas políticos institucionalizados. O modelo se apoia, metodologicamente, na reconstrução de pressuposições ideais de comunicação que, no entanto, não são pressupostos transcendentais a priori dos observadores científicos, mas são parte das expectativas e da reflexividade prática dos agentes e das instituições. Boa parte do trabalho de Habermas passa por tentar demonstrar como o constitucionalismo democrático, por um lado, e os modos de socialização, por outro, internalizam pressupostos normativos que são recuperados pelos agentes como reivindicações de validade nas práticas cotidianas, servindo como referentes empíricos da reconstrução teórica. É esse modelo normativo que fornece os critérios para os diagnósticos empíricos de "falhas na manutenção" dos procedimentos deliberativos ou mesmo de "crise" associada à obstrução sistemática das comunicações na esfera pública (HABERMAS, 2006).

O caminho aberto por Habermas sugere a necessidade de aprofundamento de uma "pragmática da crise". De acordo com Brian Milstein (2015), isso implica a tentativa de tornar mais explícito o conceito, por meio do exame de seus pressupostos e do modo como ele produz inferências sobre o mundo, informa repertórios de ação e relaciona-se com outros conceitos, revelando seu caráter reflexivo. Nele, as fronteiras entre fatos e valores, observador e participante, teoria e prática, julgamento e ação, estão menos claras. É o caráter reflexivo do conceito que permite lidar com a tensão entre os fenômenos objetivos e as experiências normativas associadas a processos e eventos que têm causas reais e efeitos reais, mas cujo status de "crise" não pode ser atribuído sem a mobilização de pressupostos normativos. Já em um segundo plano, a reflexividade do conceito aparece inteiramente vinculada ao plano da ação, falar em crise é fazer um chamado à ação, a tomar parte, responsabilizar-se pela crise, a retomar o controle sobre processos que escapam, o que distingue os diagnósticos de crise dos desastres e das tragédias que sugerem uma adaptação mais passiva diante dos processos e eventos.

Declarar crise é em si uma ação com a qual o conceito de crise é inserido na definição de uma situação, em que se afirma a existência de um objeto (que está em crise) e se propõe um compromisso mútuo, uma responsabilidade coletiva sobre a crise e a ação coletiva. Vista assim, a crise pressupõe um público, algum tipo de comunidade que pode ser acessada por meio da declaração. Ao mesmo tempo, a declaração de crise aponta um problema e reivindica uma solução que, no entanto, diferentemente de outras situações problemáticas ou mesmo de urgência ou emergência, não encontra apoio em padrões e rotinas para sua solução. Na crise, há uma proposição de que a rotina não serve e de que é preciso "experimentar", de modo que a urgência da ação é combinada com a perda dos fundamentos na doxa. E quem fala em crise reivindica certa liberdade em relação à ordem estabelecida. O diagnóstico de crise comporta uma carga de incerteza e de indeterminação, na qual estão abertas possibilidades diversas, a de linhas de ação criativa emancipatória, mas também o perigo da violência e de regressões autoritárias. 
Essa ênfase no desempenho comunicativo não deve nos afastar da "realidade" das crises. A pragmática da crise compreende um momento intermediário, o "secondness" de Charles Sanders Peirce, que se interpõe entre a concretude e a abstração, e refere-se à resistência material que desafia a interpretação e os conhecimentos tidos por garantidos, que conduz e limita as possibilidades de entendimento e de resposta. "Que algo aconteceu pode-se entender objetivamente; o que aquilo 'é' deve-se acessar discursivamente" (MILSTEIN, 2015, p. I5I). Daí a importância do entroncamento entre problemas funcionais e normativos que orienta a sociologia das crises, evitando as armadilhas do naturalismo e do construtivismo discursivo. Nela, a postulação de uma realidade nas crises não pode ser acessada sem referência ao entendimento que, por sua vez, a compõe.

A formação da "consciência de crise", que se constitui como referência para a ação, depende da formação de uma "comunidade de crise", isto é, da definição de um conjunto de pessoas que "sofrem" os efeitos da crise. No entanto, para Milstein (2015), essa comunidade não tem existência prévia, antes, ela se faz durante a crise, seria de algum modo um efeito da crise e das comunicações de crise, por meio das quais as pessoas tornam-se capazes de reconhecer reciprocamente os outros e suas reivindicações, na linha com que John Dewey interpretou a formação de "públicos" em torno de problemas.

A formação dessas comunidades de crise levanta o problema normativo das relações que estruturam as formas de reconhecimento e de participação. Potencialmente, comunidades são tanto cooperativas quanto conflitivas, o sucesso das políticas de crise vai depender de como as comunidades navegam por essas estruturas, como se constituem estruturas de tomada de decisão e relações de autoridade - que podem, inclusive, acarretar crises derivadas (ou "secundárias"), decorrentes da marginalização de pessoas afetadas pela crise nas comunidades de crise.

Esses processos conectam-se com o problema decisivo dos modos como se dão as representações das sociedades sobre si mesmas. Nesse sentido, a reflexão de Benedict Anderson sobre o nacionalismo ajuda a compreender o processo de tais representações em seus contextos. Ao mencionar as invasões sistemáticas ultramar e as ondas migratórias de árabes e chineses em comparação aos europeus, destaca que os primeiros não foram capazes de estabelecer comunidades coesas, próprias, "conscientemente crioulas" (ANDERSON, 2008, p. 26I), ainda que subordinadas a um grande centro metropolitano. Essa é a razão para que o mundo nunca visse "o nascimento de uma Nova Basra ou Nova Wuhan" (ANDERSON, 2008, p. 26I). Tais processos ajudam a compreender por que o nacionalismo surgiu primeiro no Novo Mundo, e não no Velho Mundo, o que, segundo Anderson, reforça a perspectiva eurocentrista que ainda sustenta que o nacionalismo teria surgido primeiro por lá. 
É possível acrescentar, com base no argumento de Benedict Anderson(2008) que a imaginação da comunidade guarda relação com sua constituição institucional. Foi embebida em tais imaginações de crise e objetivos de estruturação de poder paralelo ao europeu no continente americano que a engenharia federalista encontrou a figura do presidente da república, numa tentativa de salvaguardar o paralelismo com a figura do poder executivo nas mãos do rei (à la Montesquieu). A institucionalização, no entanto, guarda variações interpretativas ao longo do tempo e do espaço político, vendo-se contemporaneamente recrudescer a leitura unitarista na figura de personas como Donald Trump que, ao ocupar tal papel, exortam o chamado apelo populista contemporâneo, em claro aceno ao nacionalismo e ao exagero ou à supremacia do poder executivo na esfera de decisões, em tempos de crise. Também no Brasil, a renovação da narrativa ${ }^{3}$ sobre a figura de um pretenso poder moderador com funções de arbitragem do conflito político, embora não prevista na Constituição atual, denuncia as pretensões autoritárias. ${ }^{4}$ Não à toa a persona brasileira reivindica às forças armadas o exercício de um poder desse tipo, estimulando movimentos populistas e nacionalistas, bem como a concentração de poder nas instituições do poder executivo.

Assim, pelo que foi exposto até aqui, políticas de crise dependem e produzem representações das instituições e da sociedade. O modo como o fazem é um indicador importante para a compreensão do sentido que a crise assume em determinadas conjunturas, das possibilidades que se abrem e das tendências que se desenvolvem aí. A constituição discursiva das comunidades de crise é parte decisiva da politização das experiências de crise, sendo um processo que comporta a concorrência ou a aglutinação de distintas formas de reflexividades sociais que são ativadas nas disputas pela interpretação das crises e nas relações de poder (MAIA, 2O2I).

\footnotetext{
${ }^{3}$ A emergência de narrativas de crise durante as crises mereceria, sem dúvidas, ser estudada em seus termos próprios para uma compreensão mais ampla dos processos de formação de consciências de crise. Benedict Anderson (2008, p. 278), por exemplo, lembra que "Todas as mudanças profundas na consciência, pela sua própria natureza, trazem consigo amnésias típicas. Desses esquecimentos, em circunstâncias históricas específicas, nascem as narrativas". Tais narrativas podem ser associadas à lógica nacionalista, e também ao uso ou recurso da alusão populista em contextos de crise, tal como romances e jornais, como manchetes que exibem "falsas equivalências" e são situadas no tempo vazio e homogêneo. O autor observa que tanto as pessoas modernas quanto as nações vivem tais dilemas. A consciência de estarem incluídas no tempo serial e secular, com todas as implicações de continuidade nisso envoltas, e ao mesmo tempo, o "esquecimento" da vivência dessa continuidade, das rupturas com o passado - no caso brasileiro, por exemplo, o passado colonial, patriarcal, escravagista e latifundiário, mas também o passado da interferência militar na cena política e da ditadura.

${ }^{4}$ Nesse sentido, o parecer de junho de 2020 da Ordem dos Advogados do Brasil (OAB), que reforça a inexistência de pretenso poder moderador atribuído às Forças Armadas, bem como a inconstitucionalidade da utilização do aparato militar para intervir no exercício independente dos Poderes da República. Tal posicionamento, assinado pelo presidente nacional da OAB, Felipe Santa Cruz, pelo presidente da Comissão Nacional de Estudos Constitucionais, Marcus Vinicius Furtado Coêlho, e pelo membro da comissão, Gustavo Binenbojm, fez-se necessário após interpretações polêmicas como a do jurista Ives Gandra Martins, sobre o artigo 142 da Constituição, e atos do atual presidente da república (ver Valente, 2020).
} 


\section{Populismos, crises de legitimação e representação}

Essa abordagem ajuda a compreender o debate contemporâneo sobre "crises de legitimação" nos países ocidentais, que se segue à debacle dos mercados financeiros em 2008 e continua com o crescimento de movimentos chamados de "iliberais" e/ou "populistas" no interior dos sistemas políticos. O exame do modo como se dá a politização das experiências de crise ajuda a compreender a disputa em torno do sentido que a crise assume e as linhas "terapêuticas" disponíveis.

A crise, em sua historicidade, aparece associada ao funesto destino do neoliberalismo como teoria e política hegemônicas no Ocidente pós-guerra fria. A onipresença da palavra neoliberalismo, como argumentou Gerard Delanty (2020), pode ter ajudado as teorias críticas a denunciar as tendências de financeirização, desregulação e desacoplamento de mercados globais, mas em contrapartida tende a produzir generalizações excessivas que perdem a especificidade do objeto. De maneira mais restrita, o neoliberalismo se refere à filosofia política de Friedrich Hayek e Ludwig von Mises, os quais argumentam fundamentalmente que a liberdade econômica é o fundamento da liberdade política e se opõe ao planejamento estatal da economia (DELANTY, 2020).

$\mathrm{Na}$ qualidade de política econômica, o neoliberalismo tem outros referentes, inicialmente, as políticas de Pinochet, no Chile; Thatcher e Reagan, no Reino Unido e nos EUA, respectivamente; em articulação com o trabalho de economistas acadêmicos da Universidade de Chicago que preconizavam políticas de liberalização de mercados. A agenda de políticas que formularam implicava, de maneira mais ampla, em desregulação da economia, privatização de empresas estatais, liberalização de barreiras comerciais, redução de impostos, restrição monetária ("monetarismo") para combater inflação e políticas "antissindicais" e de desregulação do trabalho. Elas produziram, com base na variedade de sua implementação, grandes transformações nas relações entre estado e sociedade, com o retraimento das estruturas de proteção dos estados de bem-estar social constituídos no pós-guerra, em diferentes partes do mundo.

Os críticos do neoliberalismo viram nessas políticas a causa das crises desencadeadas em 2008. De acordo com vários relatos, a desregulação dos mercados financeiros redundou em bolhas especulativas, operações fictícias sem lastro na economia real; a política fiscal implicou crescimento das desigualdades sociais (PIKETTY, 2OI3); a redução da proteção social levou ao desalento e as mudanças na legislação trabalhista ao enfraquecimento da capacidade reivindicativa dos trabalhadores.

Todavia, a crise de 2008 não gerou o efeito demonstração que se podia esperar. $O$ neoliberalismo mantém sua força paradigmática entre economistas hegemônicos em universidades hegemônicas e na assessoria de grandes instituições econômicas, sua força ideológica permanece em camadas sociais diversas que continuam identificando seus interesses 
econômicos com políticas de extração neoliberal. As crises de legitimação que se seguiram a 2008 têm outro andamento, mais dilatado no tempo e com forte controvérsia política e social sobre suas causas. Há quem especule sobre uma "crise nas consciências de crise", como Milstein (2O2I), que se relaciona com as dificuldades de constituir comunidades de crise e de reconstruir espaços propriamente políticos de elaboração das experiências, para o que certamente, contribuem as transformações mais recentes nas comunicações públicas.

Aqui, mais uma vez, a discussão de Anderson pode ajudar. O autor pergunta: "Qual é a principal convenção literária do jornal?" (ANDERSON, 2008, p. 65). O que haveria em comum entre um golpe no Iraque, a descoberta de um fóssil raro no Zimbábue e um discurso de Mitterrand? Não se trata, por certo, de capricho, tampouco de algo naturalmente determinado. A arbitrariedade presente na inclusão e na justaposição de pautas mostra que um eventual vínculo entre elas precisa ser (e/ou ter sido) imaginado. Ao menos duas fontes estão na origem do vínculo produzido em um jornal: a coincidência cronológica e sua circulação comercial.

A data no alto do jornal, o seu emblema mais importante, fornece a principal conexão - o avanço do tempo vazio e homogêneo. Dentro desse tempo, "o mundo" caminha inexoravelmente em frente. [...] A segunda fonte do vínculo imaginário consiste na relação entre o jornal, como uma forma de livro, e o mercado. [...] Num sentido bem específico, o livro foi a primeira mercadoria industrial com produção em série ao estilo moderno. (ANDERSON, 2008, p. 65-66).

Anderson relembra a análise de Hegel, ao afirmar que os jornais seriam, para os modernos, um substituto das orações matinais, no silêncio e na própria consciência. Ele, no entanto, tem um caráter massivo, pois ocorre sob a simultânea impressão de que é partilhado por milhares de desconhecidos. Ficção e realidade se amalgamam silenciosamente na confiança da comunidade no anonimato característico das sociedades modernas. Há um cerimonial repetido em intervalos diários simultâneos, uma "comunidade imaginada secular, historicamente regulada pelo relógio" (ANDERSON, 2008, p.68). Na padaria, na feira, no consultório médico, réplicas escritas e visuais das notícias circulam.

As fotos e imagens que circulam por toda parte constituem fragmentos de um enorme acúmulo de evidências documentais produzidas a todo instante, que trazem ao mesmo tempo continuidade, mas também esquecimento, memórias que se perdem. Para Anderson (2008, p. 278), o conceito de pessoa, de "identidade", "não pode ser lembrada, precisa ser narrada". O autor considera que algo semelhante ao que ocorre com as pessoas modernas e suas narrativas biográficas e autobiográficas ocorre com as nações. Mas, se no caso das pessoas há começo, meio e fim, o mesmo não ocorre com as nações. As últimas não têm data certa de início, e sua morte nunca ocorre de modo natural, mas 
em forma de genocídios e holocaustos. Nesse sentido, o recuo no tempo se mostra algo inevitável, se o objetivo é buscar pela sua biografia.

Ao recuperar a biografia de uma nação, muitas vezes para servir às finalidades de uma narrativa (populista?), pode-se lembrar ou esquecer, à revelia dos índices de mortalidade. Assassinatos, execuções, guerras, holocaustos podem ser deixados de lado. Desse modo, importa recuperar suas mortes, as miríades de fatos anônimos, "que somados e tabulados em índices médios de mortalidade por século, lhe permitem mapear as condições de vida (de lenta transformação) para milhões de pessoas anônimas cuja nacionalidade seria a última coisa a ser perguntada" (ANDERSON, 2008, p. 280). Assim, é possível observar a disputa sobre a biografia das nações nas sociedades contemporâneas. Ela pode ser contada por milhares de vidas perdidas, justificadas, esquecidas, e por vezes desmerecidas pelos atores políticos que acessam a dinâmica populista para desviar a atenção das pessoas, desmerecer conquistas democráticas passadas, negar fatos do passado ao embalar narrativas de crise, e justificar decisões políticas unilaterais, decretos, invasões de parlamentos e ataques institucionais. São atos ininterruptos que marcam a aceleração do tempo e justificam decisões segundo narrativas de crise.

\section{A crítica do populismo como política de crise}

A contribuição das políticas neoliberais no retraimento dos espaços políticos e na aceleração da dinâmica decisória decorre de um programa orientado para o insulamento e a proteção do núcleo de tomada de decisões sobre política econômica em relação aos influxos oriundos dos processos democráticos de formação da vontade política. Collin Crouch (2004) alertava para os perigos da "pós-democracia", associados à captura dos processos decisórios por agentes ligados às grandes corporações empresariais. Para Wendy Brown (2015), o efeito da despolitização da economia é um enfraquecimento do "político" como um todo. Para Milstein (202I), ela mina a possibilidade de formação de um "público" de cidadãos capaz de articular terapias de crise, o que produz a "crise da consciência de crise".

Isso não leva por si à emergência dos novos movimentos de extrema direita, mas constituiria o ambiente favorável ao seu aparecimento. A ruína de uma esfera pública democrática seria uma condição para a proliferação dos ambientes sectários e conspiracionistas, tidos por livres e "alternativos", em que a propaganda populista grassa. ${ }^{5}$ Neles, a propaganda populista encontra

\footnotetext{
${ }^{5}$ Pesquisas recentes têm revelado os pressupostos de epistemologia social prevalentes nessas comunicações, em especial, a "eupistemologia", o forte apelo à busca individual de critérios de verdade, e o "conspiritualismo", que remete à associação entre teorias da conspiração e crenças espiritualistas que constituem certo ecossistema de crenças e comunicações comuns à "alt-science" e à "alt-right" populista. Ver Cesarino (2021).
} 
uma audiência e forma um público que se legitima com o enredamento complexo da noção de "povo" contraposta a "elites", e de um sentimento "dégagiste" ("que se vayan todos"), que, na expressão de Pierre Rosanvallon(202I), tem um sentido fortemente "destituinte" das estruturas de autoridade e poder existentes, favorecendo a crença, no interior dos movimentos, de que teria um sentido renovador e democrático.

A anatomia que Rosanvallon (2O2I) constitui da linguagem e da cultura política do populismo aponta para as relações fortes entre as formas de representação e a concepção de democracia em movimentos que não se restringem à extrema direita do espectro político. O populismo opõe à decadência heurística das representações sociológicas do social (classes, profissões) uma concepção homogeneizadora de "povo", constituído politicamente em contraposição a "elites" (que podem ser institucionais, culturais, científicas, o que abre também uma disputa interna intraelites, como no caso das elites médicas e a cloroquina; ou entre elites empresariais, como conglomerados Magazine Luiza versus Lojas Havan), no esquema dicotômico "amigo" × "inimigo". Ao mesmo tempo, defende uma modalidade de representação política em que a figura de uma persona encarna em si o "povo", o "homem-povo", que, sem mediações, faria do povo governo. É uma representação autorizada, unilateral, que procura eliminar a distinção entre representante e representado - e com isso restringir a possibilidade de divergência, consolidando a adesão e identidade entre eles. Em certa medida, a soberania se aproxima do caráter “irresponsável”, inimputável, excepcional (“acima das leis"), uma vez identificado por Thomas Hobbes.

Essas duas formas de representação do povo e do governante enfraquecem a democracia, pois o ataque institucional se torna regra no ambiente polarizado, assentado em formas de representação engessadas que manipulam eventuais resultados dos pleitos majoritários, ao utilizálos como carta branca ao voluntarismo dos eleitos, processo que seria supostamente mais autêntico e cuja temporalidade pode ser instantânea (via decretos). O momento eleitoral e a maioria que se constitui em torno do poder executivo são sobrevalorizados em detrimento das representações políticas plurais, do processual de representatividade democrática da circulação das ideias - como observado em Urbinati (2006) e em Faria (2020) - via parlamento, dos controles judiciários de constitucionalidade, por exemplo, depreciados como instrumentos de "elites". Plebiscitos e referendos são vistos como formas superiores de decisão, em lugar de procedimentos deliberativos voltados para produção de entendimentos, e amadurecidos em debates pluralistas.

É nesse sentido que o populismo tende a interpretar as crises segundo teorias do "bode expiatório", às vezes abertamente conspiracionistas, exacerbando o aspecto moral e o momento decisionista - salvacionista. A crise pode ser atribuída a "elites" imorais, desqualificadas como corruptas em vários sentidos, incapazes de justificar seus "privilégios". A experiência normativa da 
crise é carregada pela tensão moral, por uma política das emoções que, como forma de intelecção, ação e posicionamento mobiliza raivas, ressentimentos de "não contar nada aos olhos dos poderosos", para um confronto político que põe em descrédito as instituições existentes e assume forte caráter "destituinte". O tempo da crise é, nessa concepção, o da excepcionalidade, da urgência e das alternativas duais e mutuamente excludentes, da salvação ou da danação da comunidade política, o que contrasta ou simplesmente impede dinâmicas de "solução de problemas" ou de deliberação em situações de conflito que requerem temporalidade mais extensa e procedimentos reflexivos. ${ }^{6}$ Como argumentou Jeffrey Alexander (2019), esse tipo de mobilização solapa as possibilidades de processamento comunicativo dos conflitos na "esfera civil" e suas estruturas mais fundamentais, que constituem uma base autônoma de sustentação cultural e sociológica da democracia.

Embora expresse descontentamentos, o populismo é, como política de crise e interpretação da democracia, uma regressão. Como argumenta Rosanvallon (202I), quando consegue apoio majoritário em processos eleitorais que dão longevidade, o populismo tende a se transformar em "democratura", isto é, na perversão de regras majoritárias de decisão em regimes autoritários. Eles solapam formas pluralistas de representação da cidadania e de mediação nos processos de formação de vontades políticas. Mecanismos de controle institucional e prestação de contas não necessariamente eleitorais, não majoritários, com arranjos participativos variáveis e normatividade balizada pelo texto constitucional podem complementar e complexificar a representação da soberania popular para além de maiorias contingentes; o que permite tanto a reflexividade dos processos decisórios quanto as garantias de direitos da cidadania diante do eventual arbítrio de seus representantes. O risco do populismo é, então, exacerbar a excepcionalidade da crise e, ao abrir mão da complexificação das representações da sociedade e de sua soberania em nome da urgência, fazer ruir as estruturas que podem permitir o alargamento dos processos de constituição de públicos democráticos que possam compor linhas de superação das crises.

\section{Referências}

ALEXANDER, J. C. Frontlash/backlash: the crisis of solidarity and the threat to civil institutions.

Contemporary Sociology: A Journal of Reviews, v. 48, n. I, p. 5-II, jan. 2019.

ANDERSON, B. Comunidades imaginadas: reflexões sobre a origem e a difusão do nacionalismo. Tradução

Denise Bottman. São Paulo: Companhia das Letras, 2008.

BROWN, W. Undoing the demos: neoliberalism's stealth revolution. New York: Zone Books, 2015.

\footnotetext{
${ }^{6}$ Sobre a temporalidade das crises, ver Runciman (2016).
} 
CESARINO, L. Tratamento precoce: negacionismo ou alt-science? Blog do Labemus, 27 jul. 202 I.

Disponível em: $<$ https://blogdolabemus.com/2O2I/o7/27/tratamento-precoce-negacionismo-ou-altscience-por-leticia-cesarino/>. Acesso em: 02 ago. 2021.

CORDERO, R. Crisis and critique: on the fragile foundations of social life. Abingdon: Routledge, 2014.

CROUCH, C. Post-democracy. Malden, MA: Polity, 2004.

DELANTY, G. Critical theory and social transformation: crises of the present and future possibilities. Abingdon, Oxon; New York, NY: Routledge, 2020.

FARIA, A. Teorias da representação política. Curitiba: Appris, 2020.

HABERMAS, J. Direito e democracia: entre facticidade e validade. Rio de Janeiro: Tempo Brasileiro, 2003. 2 v.

HABERMAS, J. Legitimation crisis. Cambridge, UK: Polity Press, 1988.

HABERMAS, J. Political communication in media society: does democracy still enjoy an epistemic dimension? The impact of normative theory on empirical research. Communication Theory, v. I6, n. 4, p. 4II-426, 2006.

HABERMAS, J. Teoria do agir comunicativo. Tradução Paulo Astor Soethe. São Paulo: Martins Fontes, 2012. KOSELLECK, R. Crítica e crise. Tradução Luciana Castelo-Branco. Rio de Janeiro: Contraponto, 1999.

MAIA, F. Crise, crítica e reflexividade: problemas conceituais e teóricos na produção de diagnósticos de época. Sociologias, v. 23, n. 56, p. 212-243, 2021.

MILSTEIN, B. Thinking politically about crisis: a pragmatist perspective. European Journal of Political Theory, v. I4, n. 2, p. I4I-I60, abr. 2015.

MILSTEIN, B. What does a legitimation crisis mean today? Financialized capitalism and the crisis of crisis consciousness. In: VORMAN, B.; WEIMANN, M.(Eds.). The emergence of illiberalism: understanding aglobal phenomenon. New York: Routledge, 2O2I. p. 27-42.

PIKETTY, T. Le capital auXXIe siècle. Paris: Seuil, 2013.

PITKIN, H. Representation and democracy: uneasy alliance. In: MATHIOWETZ, D.(Ed.). Hanna Fenichel Pitkin: politics, judgment, action. New York: Routledge, 2016. p. 225 -232.

PITKIN, H. Rethinking reification. Theory and Society, v. I6, p. 263-293, 1987.

PITKIN, H. Wittgenstein and justice. On the significance of Ludwig Wittgenstein for social and political thought. Berkeley; Los Angeles; London: University of California Press, 1993.

ROSANVALLON, P. O século do populismo. Rio de Janeiro: Ateliê de Humanidades Editorial, $202 \mathrm{I}$. 
RUNCIMAN, D. What time frame makes sense for thinking about crises? In: KJAER, P. F.; OLSEN, N. (Eds.). Critical theories of crisis in Europe: from Weimar to the Euro. Reinventing critical theory. London: Rowman \& Littlefield International, 20I6. p. 3-I6.

STRYDOM, P. Contemporary critical theory and methodology. London; New York: Routledge, $20 \mathrm{II}$.

URBINATI, N. Representative democracy. Principles and genealogy. Chicago: Chicago University Press, 2006.

VALENTE, F. Freios e contrapesos - Forças Armadas não exercem papel moderador, diz parecer da OAB. Revista Consultor Jurídico, 2 jun. 2020, I6hII. Disponível em: <https://www.conjur.com.br/202O-junO2/forcas-armadas-nao-exercem-papel-moderador-oab2>. Acesso em: 08 out. 202I. 